\title{
Solvent Extraction and Spectrophotometric Determination of Nickel(II) with Thiazole-2-carbaldehyde 2-Quinolylhydrazone
}

\author{
Makoto Отомo, Tsuyoshi Watanabe and Mitsuru Moriya \\ Department of Applied Chemistry, Nagoya Institute of Technology, \\ Gokiso, Showa, Nagoya 466
}

\begin{abstract}
A sensitive method for the extractive spectrophotometric determination of nickel(II) with thiazole-2-carbaldehyde 2quinolylhydrazone (TAQH) has been described. Nickel(II) reacts with TAQH at $\mathrm{pH} 8.7-9.5$ to form a $1: 2$ metal to ligand complex that is extractable into many organic solvents. The species when extracted with benzene and measured at $522 \mathrm{~nm}$ obeys Beer's law over the range up to $0.7 \mu \mathrm{g} \mathrm{ml}^{-1}$ of nickel. The molar absorptivity is $7.17 \times 10^{4} \mathrm{I} \mathrm{mol}^{-1} \mathrm{~cm}^{-1}$ at $522 \mathrm{~nm}$. The method has been satisfactorily applied to the determination of nickel in two standard alloy steel samples.
\end{abstract}

Keywords Nickel determination, spectrophotometry, thiazole-2-carbaldehyde 2-quinolylhydrazone, solvent extraction

In a study concerning the analytical possibilities of heterocyclic substituted hydrazones as tridentate ligands, we have proposed the use of thiazole-2-carbaldehyde 2-quinolylhydrazone (TAQH) as a potential chromogenic reagent for the spectrophotometric determination of several transition metal ions including palladium. ${ }^{1}$

In this paper the properties of the nickel(II) complex with the above reagent and an extractive spectrophotometric method for determining sub-ppm amounts of nickel are described. The method has been applied to the determination of nickel in two standard alloy steel samples after separation of the metal from interfering ions by an anion-exchanger.

\section{Experimental}

\section{Reagents}

Unless otherwise stated all inorganic and organic chemicals were of reagent grade quality. Organic solvents were freshly distilled before use.

$T A Q H$ solution. The ligand, TAQH, was synthesized as described previously. ${ }^{1}$ A stock solution of $6 \times 10^{-4} \mathrm{M}$ TAQH in benzene was prepared. This solution was stable for at least 1 week, if kept in the dark.

Nickel(II) stock solution. Nickel(II) standards were obtained by dilution of $0.01 \mathrm{M}$ nickel(1I) nitrate solution standardized compleximetrically. ${ }^{2}$

Buffer solution. A solution, which is $0.1 \mathrm{M}$ in sodium tetraborate and $0.06 \mathrm{M}$ in ammonia, was adjusted to pH 9.1 with $6 \mathrm{M}$ hydrochloric acid.

lon-exchange resin. Dowex 1-X8, 50-100 mesh, was used in the chloride form. A $9 \times 60 \mathrm{~mm}$ resin bed was prepared.

\section{Apparatus}

A Nippon Bunko UVIDEC-1 digital spectrophotometer and a Union Giken SM-401 high-sensitivity recording spectrophotometer with matched $1.00-\mathrm{cm}$ quartz cells were used. A Toa Dempa HM-20E pH meter was used with a combination electrode.

All measurements were made at $25^{\circ} \mathrm{C}$.

\section{Procedure}

General procedure for the determination of nickel(II). Transfer an aliquot of sample solution containing up to $7 \mu \mathrm{g}$ of nickel(II) into a 50-ml separatory funnel. Add $5 \mathrm{ml}$ of the buffer solution ( $\mathrm{pH} \mathrm{9.1)} \mathrm{and} \mathrm{dilute} \mathrm{to}$ $10 \mathrm{ml}$ with doubly distilled water. Equilibrate the mixture with exactly $10 \mathrm{ml}$ of $6 \times 10^{-4} \mathrm{M} \mathrm{TAQH}$ in benzene by mechanical shaking for $30 \mathrm{~min}$. Measure the absorbance of the organic phase at $522 \mathrm{~nm}$ against the reagent blank.

Determination of nickel in alloy steel samples. Dissolve $0.1 \mathrm{~g}$ of the finely pulverized sample in $10 \mathrm{ml}$ of concentrated hydrochloric acid plus $5 \mathrm{ml}$ of concentrated nitric acid and evaporate almost to dryness on a water-bath. Repeat the acid treatment and evaporation to ensure complete dissolution of the soluble components of the sample. Add $10 \mathrm{ml}$ of hot, $1 \mathrm{M}$ hydrochloric acid and remove insoluble residue by filtration. Dilute the filtrate to $250 \mathrm{ml}$ with water. Use a suitable aliquot of this solution for the nickel(II) determination.

Acidify the sample solution to approximately $9 \mathrm{M}$ in 
hydrochloric acid and place on the anion-exchange column. Elute the column with $20-25 \mathrm{ml}$ of $9 \mathrm{M}$ hydrochloric acid at a flow rate of $0.6 \mathrm{ml} \mathrm{min}$. Evaporate the effluent to dryness and determine nickel(II) as described.

\section{Results and Discussion}

\section{Characteristics of nickel(II)-TAQH complex}

The nickel(II)-TAQH complex is sparingly soluble in water, but readily soluble in aromatic hydrocarbons, halogenated hydrocarbons, acetate esters and ketones. The spectral characteristics of the complex depend on the solvent used. Benzene was chosen as the extractant because the highest absorbance of the complex in the visible region was obtained in this solvent. Under the optimum conditions of the reagent and ammonia concentrations, $\mathrm{pH}$ and shaking period, nickel(II) can be quantitatively extracted from aqueous solution with one $10-\mathrm{ml}$ portion of TAQH in benzene over the

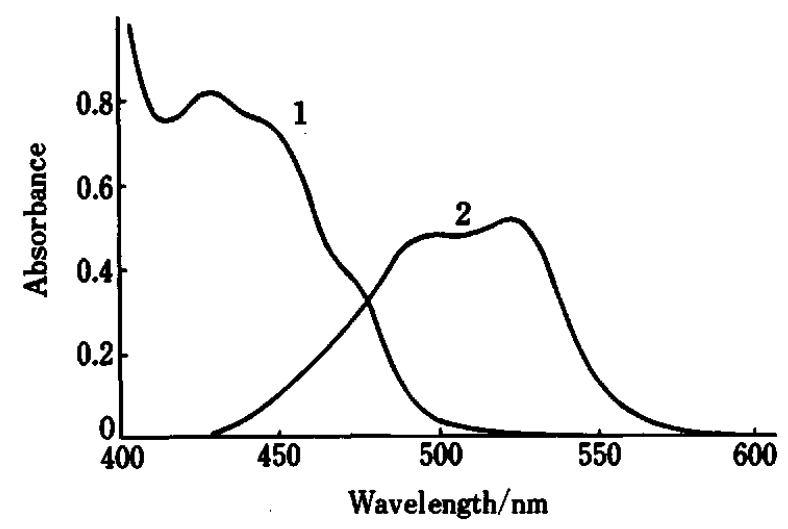

Fig. 1 Absorption spectra obtained under experimental conditions given in the general procedure. Ni(II) taken, $4.1 \mu g$; (1) reagent blank vs. benzene; (2) Ni(II)TAQH complex $v s$. reagent blank.

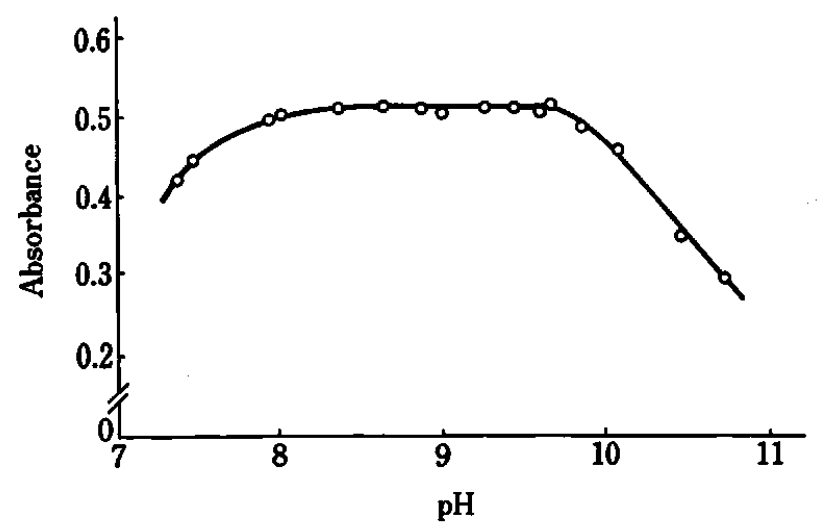

Fig. 2 Effect of pH. Ni(II) taken, 4.1 $\mu \mathrm{g}$; TAQH used, 6X $10^{-4} \mathrm{M} ; \mathrm{NH}_{3}$ added, $0.03 \mathrm{M}$. concentration range studied. The absorption spectra of the reagent and the nickel(II) complex in benzene are shown in Fig. 1. The absorbance measurements were made at $522 \mathrm{~nm}$.

\section{Effects of experimental conditions}

Figure 2 illustrates the dependence of the absorbance of the organic phase on the $\mathrm{pH}$ of the aqueous phase. A maximum and constant absorbance is obtained between $\mathrm{pH} 8.7$ and 9.5. For the spectrophotometric determination $\mathrm{pH} 9.1 \pm 0.1$ was adopted. Addition of $9 \times 10^{-3}-3.3 \times 10^{-2} \mathrm{M}$ ammonia as an auxiliary complexing agent was effective to some extent for improving the slow chelate formation between nickel(II) and TAQH.

The absorbance of the organic phase was studied as a function of the initial concentration of TAQH in benzene. It was found that about a 50-fold molar excess of TAQH was the minimum required for obtaining a constant and maximum absorbance. A $6 \times 10^{-4} \mathrm{M}$ solution of TAQH is recommended as a suitable concentration of reagent.

A shaking period of 20-60 min did not produce any change in absorbance, provided the volume ratio $V_{\text {org }}(10 \mathrm{ml}): V_{\text {aq }}$ was between 1:0.5 and 1:2; a shaking time of $30 \mathrm{~min}$ was selected.

\section{Stoichiometry}

The extraction method ${ }^{3,4}$, where metal distribution is followed in the presence of a reasonable excess of ligand, was used to establish the stoichiometry of the nickel(II) complex. As the ligand, TAQH, exists in the neutral form, HL, at the acidity investigated', a simple logarithmic expression can be derived for the metal distribution:

$$
\log D_{\mathrm{Ni}}=\log K_{\mathrm{ex}}-\log \alpha_{\mathrm{Ni}}+n \log [\mathrm{HL}]_{\mathrm{org}}-n \log \left[\mathrm{H}^{+}\right]
$$

where $D_{\mathrm{Ni}}$ denotes the distribution ratio of nickel(II), $K_{\text {ex }}$ is the extraction constant defined by [ $\left[\mathrm{NiL}_{n}\right]_{\text {org }}$ $\left[\mathrm{H}^{+}\right]^{n} /\left[\mathrm{Ni}^{2+}\right][\mathrm{HL}]_{\text {org }}^{n}, n$ is the number of hydrazone molecules bound per metal atom, and $\alpha_{\mathrm{Ni}}$ is the sidereaction coefficient for nickel(II). At constant $\mathrm{pH}$, a logarithmic plot of the metal distribution against the ligand concentration in the organic phase should be a straight line with slope equal to $n$. Experimental data showed $n$ equal to 2 and a 1:2 Ni(II):ligand ratio (Fig. 3 ). The value of $K_{\text {ex }}$ was estimated to be $8.1_{3} \times 10^{-10}$, by using $\alpha_{\mathrm{N}}=27.4$. $^{5}$

\section{Beer's law and sensitivity}

A calibration graph for the determination of nickel(II) was prepared according to the general procedure. A good linearity was obtained between the absorbance of the organic phase and the concentration of nickel(II) up to about $1.2 \times 10^{-5} \mathrm{M}\left(0.7 \mu \mathrm{g} \mathrm{ml}^{-1}\right)$. The molar absorptivity of the complex and the Sandell sensitivity are $7.17 \times 10^{4} 1 \mathrm{~mol}^{-1} \mathrm{~cm}^{-1}$ at $522 \mathrm{~nm}$ and 0.86 $\mathrm{ng} \mathrm{cm}{ }^{-2}$, respectively. In the sensitivity for nickel(II), 


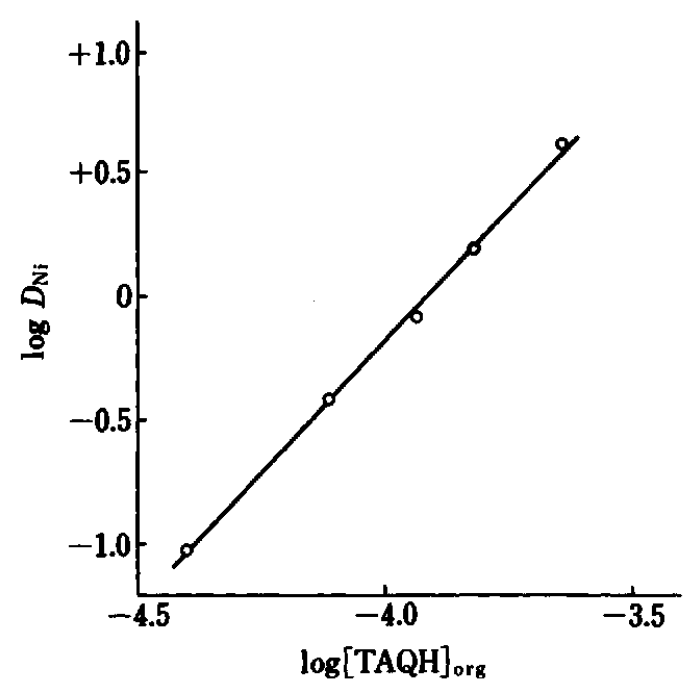

Fig. 3 Relationship between nickel(II) distribution and analytical TAQH concentration. Ni(II) taken, $7.0 \times 10^{-6}$ $\mathrm{M} ; \mathrm{pH}, 9.15 ; \mathrm{NH}_{3}$ added, $0.03 \mathrm{M}$.

the present reagent, TAQH, is fairly or much superior to other $N N N$-tridentate ferroin-type hydrazones, such as pyridine-2-aldehyde-2-pyridylhydrazone ${ }^{6}$, pyridine2-aldehyde-2-quinolylhydrazone ${ }^{7}$, quinoline-2-aldehyde2-quinolylhydrazone $e^{8}$, pyridine-2-aldehyde-2-benzothiazolylhydrazone ${ }^{9}$, phenanthridine-6-aldehyde-2-pyridylhydrazone $^{8}, 2,2^{\prime}$-dipyridyl-2-pyrimidinylhydrazone ${ }^{10}$, benzothiazole-2-aldehyde-2-benzothiazolylhydrazone ${ }^{11}$ and some pyradinylhydrazones. ${ }^{12}$ TAQH is also more sensitive for nickel(II) than familiar colorimetric reagents, such as dimethylglyoxime (extraction method) ${ }^{13}$, $2,2^{\prime}$-furil dioxime ${ }^{14}, 1,2$-cyclohexanedionedioxime ${ }^{15}$ and 1-(2-pyridylazo)-2-naphthol. ${ }^{16}$

\section{Effect of diverse ions}

The possible interference of various ions was examined by introducing them into a solution containing $4.1 \mu \mathrm{g}$ of nickel(II). The tolerance limit of an ion was fixed as the maximum amount causing an error not greater than $\pm 2 \%$ in the absorbance of the extract solution. The results for metallic ions are summarized in Table 1. Of the non-metallic anions tested, chloride, bromide, fluoride, nitrite, nitrate, thiosulfate and sulfate up to at least 10000 -fold molar ratio to nickel(II), and iodide, thiocyanate, sulfite, oxalate and tartrate up to 1000-fold molar amount did not interfere with the determination. Cyanide, citrate and EDTA, however, must be absent.

\section{Application to alloy steel samples}

The proposed method has been applied to the determination of nickel in two standard alloy steel samples supplied by the Iron and Steel Institute of Japan.

In basic media, as shown in Table $1, T A Q H$ reacts with several metal ions including cobalt(II), copper(II), zinc(II), bismuth(III), chromium(III), iron(II,III), tho-
Table 1 Effect of metallic ions on determination of $4.1 \mu \mathrm{g}$ $(0.070 \mu \mathrm{mol})$ of nickel

\begin{tabular}{|c|c|}
\hline $\begin{array}{l}\text { Tolerance limit } \\
\text { ([Ion]/[Ni(II)]) }\end{array}$ & Ion \\
\hline $\begin{array}{c}140 \\
\text { (at least) }\end{array}$ & $\begin{array}{l}\mathrm{Ag}(\mathrm{I}), \mathrm{Tl}(\mathrm{I}), \mathrm{Ba}(\mathrm{II}), \mathrm{Ca}(\mathrm{II}), \mathrm{Mg}(\mathrm{II}), \\
\mathrm{Mn}(\mathrm{II}), \mathrm{Pb}(\mathrm{II}), \mathrm{Sr}(\mathrm{II}), \mathrm{La}(\mathrm{III}), \mathrm{Sm}(\mathrm{III}), \\
\mathrm{Pt}(\mathrm{IV}), \mathrm{Se}(\mathrm{IV}), \mathrm{As}(\mathrm{V}), \mathrm{V}(\mathrm{V}), \mathrm{Cr}(\mathrm{VI}), \\
\mathrm{Mo}(\mathrm{VI})\end{array}$ \\
\hline 70 & $\operatorname{Ir}(\mathrm{III}), \mathrm{U}(\mathrm{VI})$ \\
\hline 30 & $\begin{array}{l}\mathrm{Pd}(\mathrm{II}), \mathrm{Pt}(\mathrm{II}), \mathrm{Au}(\mathrm{III}), \mathrm{Ga}(\mathrm{III}), \operatorname{Re}(\mathrm{III}), \\
\text { Y(III), W(VI), Os(VIII) }\end{array}$ \\
\hline 7 & $\operatorname{Al}(I I I)^{2}, \operatorname{In}(I I I)^{a}, \operatorname{Th}(I V)^{a}$ \\
\hline 3 & $\mathrm{Cr}(\mathrm{III}), \mathrm{Ti}(\mathrm{IV})^{\mathrm{a}}, \mathrm{Zr}(\mathrm{IV})^{\mathrm{a}}$ \\
\hline $0-1$ & $\begin{array}{l}\mathrm{Cd}(\mathrm{II}), \mathrm{Co}(\mathrm{II}), \mathrm{Cu}(\mathrm{II}), \mathrm{Fe}(\mathrm{II}, \mathrm{III}), \\
\mathrm{Hg}(\mathrm{II}), \mathrm{Zn}(\mathrm{II}), \mathrm{Bi}(\mathrm{III}), \mathrm{Rh}(\mathrm{III}), \mathrm{Ru}(\mathrm{III})\end{array}$ \\
\hline
\end{tabular}

a. In the presence of $0.07 \mathrm{M}$ sodium fluoride.

Table 2 Determination of nickel in standard alloy steel samples

\begin{tabular}{clcc}
\hline \multirow{2}{*}{ Sample } & Composition, \% & \multicolumn{2}{c}{ Ni content, \% } \\
\cline { 3 - 4 } & & Standard & Found \\
\hline JSIS 153-1 & C 0.24, Si 0.23, & $1.06^{\mathrm{a}}$ & 1.04 \\
& Mn 0.77, P 0.049, & & 1.05 \\
& S 0.018, Cu 0.13, & & \\
& Cr 1.10, Mo 1.26, & & \\
& V 0.22 & & \\
JSIS 154-1 & C 0.29, Si 0.57, & $0.51^{\mathrm{b}}$ & 0.50 \\
& Mn 1.04, P 0.015, & & 0.49 \\
& S 0.016, Cu 0.21, & & \\
& Cr 1.95, Mo 0.68, & \\
& V 0.32 \\
\hline
\end{tabular}

a. An average of 24 analytical data ranging from 1.02 to $1.10 \%$. b. An average of 24 analytical data ranging from 0.49 to $0.53 \%$.

dium(III) and titanium(IV) to give extractable colored complexes or insoluble precipitates on the boundary of the two phases. A preliminary anion-exchange separation of nickel(II) was therefore adopted for eliminating the possible interference from metal ions, prior to the color development of the nickel(II)-TAQH complex. It was found that under the experimental conditions described, the anion-exchange column permits quantitative separation of nickel(II) $(4.1 \mu \mathrm{g})$ from each of the following metal ions: cadmium(II), cobalt(II), copper(II), mercury(II), palladium(II) and iron(III) up to at least 100-fold molar amount; iron(II), zinc(II) and bismuth(III) up to about 50-fold molar amount. However, more than 4- to 5-fold molar amounts of chromium(III) and titanium(IV) still interfered with the final determination of nickel(II) by suppressing the color formation of the TAQH complex.

The analytical results shown in Table 2 are in 
reasonable agreement with the standard values.

In conclusion, the tridentate hydrazone ligand, $\mathrm{TAQH}$, is worthy of use as a chromogenic reagent for the spectrophotometric determination of nickel(II) at sub-ppm levels.

\section{References}

1. T. Nakagawa, K. Doi and M. Otomo, Analyst [London], 110, 387 (1985).

2. K. Ueno, "Compleximetric Titration (in Japanese)", p. 358, Nankodo, Tokyo (1972).

3. A. K. De, S. M. Khopkar and R. A. Chalmers, "Solvent Extraction of Metals", p. 11, Van Nostrand, London (1970).

4. J. Inczédy, “Analytical Applications of Complex Equilibria (J. Tyson, transl.)”, p. 260, Wiley, New York (1976).

5. Obtained from the stability constants for nickel(II) ammine complexes, $\log \beta_{1}=2.81, \log \beta_{2}=5.08, \log \beta_{3}=$ 6.85, $\log \beta_{4}=8.12, \log \beta_{5}=8.93$ and $\log \beta_{6}=9.08$ : "Critical Stability Constants", Vol. IV, p. 40, ed. R. M. Smith and A. E. Martell, Plenum, New York (1976).
6. M. A. Quddus and C. F. Bell, Anal. Chim. Acta, 42, 503 (1968).

7. S. P. Singhal and D. E. Ryan, Anal. Chim. Acta, 37, 91 (1967).

8. V. Zatka, J. Abraham, J. Holzbecher and D. E. Ryan, Anal. Chim. Acta, 54, 65 (1971).

9. M. L. Heit and D. E. Ryan, Anal. Chim. Acta, 32, 448 (1965).

10. R. B. Singh, P. Jain and R. P. Singh, Talanta, 29, 77 (1982).

11. T. Uno and S. Akihama, Bunseki Kagaku, 10, 822 (1961).

12. A. A. Schilt, P. C. Quinn and C. L. Johnson, Talanta, 26, 373 (1979).

13. W. Nielsch, Fresenius' Z. Anal. Chem., 143, 272 (1954).

14. J. S. Forrester and J. L. Jones, Anal. Chem., 32, 1443 (1960).

15. R. C. Ferguson and C. V. Banks, Anal. Chem., 23, 448 (1951).

16. T. Dono, G. Nakagawa and H. Wada, Nippon Kagaku Zasshi, 82, 590 (1961).

(Received September 9, 1986)

(Accepted September 27, 1986) 